\title{
RIGHTS, COMPENSATION, AND CULPABILITY
}

\section{By: MICHAEL J. ZIMMERMAN}

Zimmerman, Michael J. "Rights, Compensation, and Culpability," Law and Philosophy, 13 (1994): 419-450.

Made available courtesy of Springer Verlag.

The original publication is available at www.springerlink.com

***Note: Figures may be missing from this format of the document

Article:

Philosophers and laymen alike are strongly attracted to the view that the infringement of a right calls for compensation. Consider this case posed by Joel Feinberg:

Suppose that you are on a back-packing trip in the high mountain country when an unanticipated blizzard strikes the area with such ferocity that your life is imperiled. Fortunately, you stumble onto an unoccupied cabin, locked and boarded up for the winter, clearly somebody else's private property. You smash in a window, enter, and huddle in a corner for three days until the storm abates. During this period you help yourself to your unknown benefactor's food supply and burn his wooden furniture in the fireplace to keep warm. Surely you are justified in doing all these things, and yet you have infringed the clear rights of another person. ... We would not think it inappropriate to express our gratitude to the homeowner, after the fact, and our regrets for the damage we have inflicted on his property. More importantly, almost everyone would agree that you owe compensation to the homeowner for the depletion of his larder, the breaking of his window, and the destruction of his furniture. One owes compensation here for the same reason one must repay a debt or return what one has borrowed. If the other had no right that was infringed in the first place, one could hardly have a duty to compensate him. Perhaps he would be an appropriate object of your sympathy or patronage or charity, but those are quite different from compensation. ${ }^{1}$

Surely Feinberg is right in saying that almost everyone would agree that compensation is owed in this case. That it is owed is a claim that has been explicitly endorsed by other philosophers, in particular Judith Thomson. ${ }^{2}$ But it is a claim that I suspect is false, and in this paper I shall try to explain why. ${ }^{3}$ I don't suppose that what follows is a conclusive refutation of the claim; but if it succeeds in casting serious doubt on the claim, then a particularly strong intuition will have been to that extent undermined.

\section{Part I.}

Exactly what is the claim at issue? We can begin with this:

(1a) If A has infringed a (claim-)right of B's, then A must compensate B for B's loss. 
One might take issue with the term "compensation." Is it sufficiently general? Frequently the term connotes making amends in some material manner, and perhaps this is the sort of compensation that most would say is called for in Feinberg's case. But in other cases "making it up" to the person who has been wronged would appear only to call for the performance of some service (where the service may be as minimal as making an apology or providing an explanation for the infringement of the right). Does this constitute "compensation"? I shall assume so. No other term strikes me as more suitable. "Amends" itself would seem in many cases too weak, and "reparation," "restitution," "redress," and the like seem to me even less appropriate as candidates for the general term that is needed.

Still, (1a) needs refinement. First, it is clear that the "must" must be regarded as expressing a prima facie duty, as opposed to an overall duty. For certainly it can happen that considerations that oppose compensation on occasion prevail over those that favor it. (It may happen that the only way in which A can compensate B is to pay B ten dollars, but A already owes his last ten dollars to C, who is in much greater need of it than either A or B is.) Second, it is clear that the duty that $\mathrm{A}$ has (or is alleged to have) is one that he owes B in particular; for it is B whose right has been infringed. Thus the duty of compensation concerns B in two ways: it is B who is to be compensated, and it is to B that the duty is owed. ${ }^{4}$ And so we must move from (1a) to:

(1b) If A has infringed a right of B's, then A has a prima facie duty to B to compensate B for B's loss.

This isn't enough, though. Presumably the duty of compensation is alleged to arise simply in virtue of the fact that A has infringed a right of B's. And so:

(1c) If $\mathrm{A}$ has infringed a right of B's, then $\mathrm{A}$ has a prima facie duty to $\mathrm{B}$, in virtue of this fact (that A has infringed a right of B's) alone, to compensate B for B's loss.

Here, for reasons that will emerge later, "this fact alone" is to be understood to include all facts that the fact of infringement entails and all facts upon which these entailed facts themselves supervene.

And still this can't be quite right. First, B may waive his (alleged) right to compensation. (I am assuming that $\mathrm{A}$ has a duty to $\mathrm{B}$ to compensate $\mathrm{B}$ only if $\mathrm{B}$ has a claim-right against $\mathrm{A}$ that $\mathrm{A}$ compensate B.) Second, it may happen that A cannot compensate B (for a variety of reasons: A dies, B dies, or something less dramatic); and if (as I assume) "has a prima facie duty to" implies "can," then (1c) won't do. Third, B may suffer no loss, in which case there is nothing to be compensated. (Must every infringement of a right involve a loss? Why?) Fourth, A may take out some (morally acceptable) form of insurance against being required to compensate the victims of certain of his transgressions, in which case it is not A but his insuror who, if anyone, owes B compensation. Even in this case, though, we might say that the onus of compensating B lies with A; either he must do it himself, or he must arrange for someone else to do it.

And so we reach this formulation: 
(1d) If A has infringed a right of B's, then A has a prima facie duty to B, in virtue of this fact alone, so to act that B is compensated for his loss, if any, if he can and if B has not waived his claim to such compensation.

Now, it may be that further refinement is called for. (This is one possible response to the criticisms that I shall adduce; I shall address it in Section VIII below.) But for the time being I shall take it that (1d) expresses the claim that is at issue, and it is this claim that I shall call into question.

\section{Part II.}

Consider the following:

(2) If A has infringed a right of B's, then A ought to be forced to compensate B for B's loss.

It is clear that whatever (2) means exactly, it means something different from what (id) means. Still, it will be useful to take explicit note of the main difference, and that is that what is said in (2) to be required is that A be forced (by someone, perhaps the government) to compensate B. The "ought" (whether it expresses a duty — the "ought-to-do" — or merely an ideal — the "ought-to-be"; whether it applies all things considered or merely prima facie) attaches to the action of someone forcing A to compensate B, and not to the action of A's compensating B. Of course, some may think that (2) is true because they take (id) to be true; that is, they may think that A's having a duty to B to compensate B makes it the case that A ought to be forced to compensate B (if he would otherwise not compensate B). What I wish to point out here is that it is possible that (2) be true even if (1d) is false; that is, it may be that A ought to be forced to compensate B even though A doesn't have a duty to B to compensate B. One possible reason for saying so is this: making rights-infringers liable in this way constitutes a deterrent to further rights-infringements. Another possible reason is this: even if not all rights-infringers owe compensation, many do, and it is impossible administratively to distinguish between the two classes.

Still, I should say this. I think that it is much harder to argue for (2) without using (1d) as a basis than it is to argue for it using (1d) as a basis; it is harder still if a certain other proposition - (6), below - is true, as I shall urge. Thus, although my immediate concern here is with the truth of (id), my remarks are intended to cast some doubt on (2) also.

\section{Part III.}

We should distinguish the following propositions:

(3) A has infringed a right of B's;

(4) A has violated (that is, wrongly or unjustifiably infringed) a right of B's;

(5) A has culpably infringed a right of B's.

Each of (4) and (5) of course entails (3), but the reverse is not true. That (3) does not entail (4) (whose "wrongly or unjustifiably" is to be construed as expressing wrongdoing overall or all things considered) is due to the fact that B's right may be merely prima facie, as in Feinberg's case. That (3) does not entail (5) is due to the fact that A may have an excuse for infringing B's 
right. (I would say, also, that (4) neither entails nor is entailed by (5), but this is not directly pertinent to the present issue. $)^{5}$

Both (4) and (5) may be understood to imply that A was, in some sense, at fault in infringing B's right. This is not implied by (3), and this is what makes (1d) so interesting: fault is not said to be a precondition for the duty to compensate. Clearly this is intended by Feinberg and Thomson; when you break into the cabin and burn the furniture, there is no question of your being at fault in doing so, but still you are alleged to owe the homeowner compensation.

(Feinberg and Thomson in fact take your duty to compensate in the cabin-case to be a sign that a right has been infringed even though you have acted justifiably — evidence, that is, that (3) indeed falls short of (4), in that the latter entails but is not entailed by the former. They claim that the duty to compensate is explained by the fact that a right has been infringed. ${ }^{6}$ I would of course dispute this. I agree that it is possible to infringe a right without violating it, but since I am inclined to deny that there is a duty to compensate in such cases, I would not take such a duty to be reason to accept the possibility of justifiably infringing a right. ${ }^{7}$

\section{Part IV.}

I have granted that almost everyone will agree with Feinberg and Thomson. Why, then, think (1d) false? Well, we should first ask: why think it true? Shelly Kagan considers this answer:

If an agent refuses to compensate her victim, then she is causing further harm, beyond the original harm - that is, the further harm consisting of the victim's continuing suffering. Since it is forbidden to cause harm, this is true of the further harm the agent is causing, and not only the original harm. So it is wrong for the agent to refuse to compensate her victim: it violates the victim's right not to be harmed. ${ }^{8}$

Of course, this applies at best only to those rights-infringements that involve harm, and perhaps not all do. Still, we could substitute "loss" for "harm" here, and then the thesis would apply to all those rights-infringements covered by (1d). The fact is, as Kagan correctly notes, this defense of (1d) fails, for it founders on the distinction between doing harm and allowing harm.

Once the "original" harm is done by the agent, all that that agent is doing is allowing that harm to go uncorrected. If we want, we can even speak of the continuation of the harm as a "further" harm. But it remains the case that the agent is only allowing that further harm, exactly like everyone else who is in a position to do something about it but fails to. Since the agent is not actively causing the further harm, she cannot be said to be constantly violating the victim's right not to be harmed. ${ }^{9}$

Kagan contends that it might happen in some cases that a failure to compensate constitutes a failure to minimize the original harm done; in such a case, a failure to compensate constitutes a continuation of the original rights-infringement. If this is possible, then A's duty to compensate B may be seen to be a "part" of A's original duty not to infringe B's original right, and since it is presupposed that $\mathrm{A}$ and $\mathrm{B}$ have the original duty and right, respectively, there is no problem here in acknowledging A's duty to compensate B. Fair enough. But in those cases (and Feinberg's case is surely one) where it seems intuitively correct to say that the original harm has been completed, 
then, as Kagan rightly insists, the alleged duty to compensate for the harm cannot be accounted for in this way.

Still, Kagan is, like most others, of the opinion that A does owe B compensation. He thinks that the best way to account for this would be somehow to establish that the ground for B's original right (and thus of A's original duty) itself constitutes the ground for B's subsequent right to be compensated (and thus of A's duty to compensate B). As he says: "[W]hatever it is that generates a right not to be harmed in the first place also generates a right to compensation." ${ }^{10}$ But he candidly confesses himself unable to establish this. Let us look into this matter for a moment.

First, what is the ground for B's original right? Clearly, once we abstract from "the" right not to be harmed to other rights, we cannot answer this question in the absence of a specification of the right at issue; the ground will vary from case to case. But, second, what is the ground for B's (alleged) subsequent right to compensation? This has been identified (in (1d)) as simply the fact that B's original right was infringed. Doesn't this show that the grounds of these two rights must be different and hence that Kagan's suggestion fails?

No; for the suggestion has been put too roughly. What Kagan says elsewhere is this:

[T]he position must be something like the following. There are certain facts that ground or generate a right not to be harmed. In certain cases this right will be violated, or at least infringed. If it is, then those same underlying facts (together with the fact of violation, and so on) must in turn generate a right to be ... compensated by the agent who . . infringed the right. ${ }^{11}$

I have emphasized the parenthetical remark, for it is crucial. It is misleading to say that the ground of B's original right and the ground of his (alleged) subsequent right to compensation must be identical. Rather, the ground of the latter includes the ground of the former plus the fact that the former has been infringed. This is, indeed, exactly what (1d) claims. When (1d) says that it is in virtue simply of the fact that A has infringed B's original right that A owes B compensation, what is meant (as noted earlier) is that it is in virtue of this fact and all facts that this fact entails and upon which these entailed facts themselves supervene (thus including the entailed fact that B had the original right, which itself supervenes upon the grounds of that original right). Thus there is no criticism here of Kagan's suggestion; on the contrary, (1d) is wholly in keeping with it.

But we still have no defense of (1d). So, again, why think it true? I know of only two arguments in the literature that seem at all relevant. One is given by Thomson, who says:

Let us suppose that B is injured, and that A did not cause the injury, indeed, that he in no way causally contributed to B's injury. Then whatever did in fact cause B's injury — whether it was B himself who caused his injury, or whether his injury was due entirely to natural causes, or whether C or D caused it - there is nothing true of A which rules out that B's injury [was caused by B himself], and therefore nothing true of A which rules out that B should bear his own costs. Everything true of A is compatible with its being the case that B's costs should lie where they fell. So there is no feature of A which marks his pockets as open 
to $\mathrm{B}-\mathrm{B}$ is no more entitled to call on $\mathrm{A}$ than he is entitled to call on any person $\mathrm{X}$ chosen at random.

Causality matters to us, then, because if A did not cause (or even causally contribute to) B's injury, then A's freedom of action protects him against liability for B's costs. ${ }^{12}$

But even if we agree with what Thomson says here, we do not get the sort of link between causation (rights-infringement) and liability (the duty to compensate) that is at issue in (1d). At best what we have is the contention that, if $\mathrm{A}$ has not infringed a right of B's, then A does not owe B compensation. ${ }^{13}$ We cannot infer from this that, if $\mathrm{A}$ has infringed a right of B's, then $\mathrm{A}$ does owe B compensation.

The other argument that might be relevant to a defense of (1d) is one that has been given by Tony Honore. I shall consider it in Section VII below Up to this point, then, I conclude that other than its admittedly strong intuitive plausibility (if this constitutes a reason at all) — we have been given no reason to accept (1d).

\section{Part V.}

Let us now turn to reasons to doubt (id). One reason might stem from a thesis that Thomson herself endorses. She calls it the Limits Thesis, and it reads as follows:

$\mathrm{X}$ has a claim against $\mathrm{Y}$ that $\mathrm{Y}$ not do alpha if and only if either

(i) X's claim is a pure social claim, or

(ii) Y's doing alpha either

(a) itself would be Y's committing trespass on $\mathrm{X}$, or causing $\mathrm{X}$ harm or nonbelief-mediated distress, or

(b) is a means by which Y would be committing trespass on $\mathrm{X}$, or causing $\mathrm{X}$ harm or non-belief-mediated distress. ${ }^{14}$

By "a pure social claim" Thomson means a claim that is generated purely socially, by way of private commitment or law. Presumably the alleged claim to compensation is not such a claim, at lease when the original right that has been infringed is not such a claim. By "trespass" Thomson means bodily intrusion or invasion. Presumably the failure to compensate does not constitute such intrusion or invasion, nor must it constitute the means to such intrusion or invasion. Thomson doesn't say exactly what she takes harm to be, but she does say that Y causes X harm only if Y causes (whether by action or omission) X to be worse off than X was before. ${ }^{15}$ Presumably the failure to compensate need not cause harm or be a means by which harm is caused, in this sense of "harm." By "non-belief-mediated distress" Thomson means a feeling which the person who experiences it dislikes and which is not mediated by some belief. Examples that she gives of such distress include feelings of pain, nausea, and dizziness; examples that she gives of belief-mediated distress include the feelings of fear, disappointment, and grief. ${ }^{16}$ Presumably the failure to compensate does not in all cases cause non-belief-mediated distress or constitute a means by which such distress is caused.

It appears to me, then, that Thomson's apparent endorsement of (Id) is at odds with her endorsement of the Limits Thesis. If there is reason to endorse the Limits Thesis, there is thus to 
that extent reason to doubt (Id). Of course, it might be argued that the inconsistency between the Limits Thesis and (1d) is merely apparent, or that it is the Limits Thesis, and not (1d), that should be discarded. Nonetheless, in the absence of such argument, and assuming that the Limits Thesis has some appeal, we would appear to have some reason to doubt (1d). ${ }^{17}$

\section{Part VI.}

So far, though, we have constructed at best a weak case against (1d). A stronger case seems to me to stem from a consideration of the moral status of the agent, A, when A causes B the loss in question. Let us take, as an example of causing such a loss, bringing about a certain harm: a broken arm. Thus A breaks B's arm. Let us suppose that B has a right not to be harmed in this way. Does it follow that A owes B compensation for this? Clearly not. There are cases and cases.

Suppose that A is a hurricane (Hurricane Andrew, say). Such an agent of harm clearly cannot have a duty to compensate, since it can neither have duties nor compensate.

Suppose that A is a gorilla. Can such an agent have duties? One is first moved, I think, to deny that it can, although it is not easy to say why. One view, which Thomson calls Kantian and which she endorses, is that the capacity to conform one's conduct to the moral law (that is, to act in a certain way because one sees it as one's duty to do so) is both necessary and sufficient for the moral law to apply to one (that is, for it to be the case that one has, or at least can have, a duty). ${ }^{18}$ No doubt this view has some intuitive appeal, although it is hard to see how it might be defended. (It is doubtful, for instance, that an analogous claim is true for positive law.) At any rate, if the view is correct, then presumably a gorilla can have no duties (since presumably it lacks the concept of duty and therefore cannot act in a certain way because it sees it as its duty to do so), and so it cannot have a duty to compensate. On the other hand, it is sometimes claimed that, as long as one has options, one can have duties, ${ }^{19}$ and perhaps we can say that a gorilla, unlike a hurricane, has a genuine choice whether or not to act in a certain way (a way that will in fact result in B's arm being broken). If so, a gorilla can have duties, on this view. (This is not of course to say that a gorilla can be culpable for its actions. It cannot, for being culpable surely does require, even if being bound by duty does not, that one have the concept of duty.) ${ }^{20}$

Can a gorilla compensate its victims? This too is unclear to me. Clearly it cannot do so intentionally; but perhaps it can be pressed into a sort of service that provides some form of compensation.

Suppose that A, the agent of the harm that consists in B's arm being broken, is not a hurricane or a gorilla but an infant. Here, too, it is not clear just what to say. If the Kantian view is true, then an infant, like a gorilla, has no duties. If the weaker, options view is true, an infant will have duties if and only if it can have genuine options; whether it can is unclear to me. Similarly, whether or not an infant could do something by way of compensation is unclear. Here, though, there is an added complication. Even if we believe that an infant can have no duties and cannot compensate, it will, under normal circumstances, become such that it has these capacities. This might be taken as reason to hold the duty to compensate in abeyance, as it were, until such time as it can be discharged. 
Finally, suppose that A is a full-fledged, normal, adult human being. In such a case, A surely can have duties and can compensate and so, according to (1d), A does have the duty to compensate B for B's broken arm (provided that the other conditions mentioned in (1d) are satisfied).

Thus we have four agents, of two of which it is clear what to say: the hurricane has no duty to compensate B, while the adult (if (1d) is true) has a duty to compensate B. What to say of the gorilla and the infant is not so clear to me, although I imagine that most people would say that neither of these agents has a duty to compensate B. Let us suppose, for simplicity of exposition, that this view is correct, and thus that only the adult (at best) has a duty to compensate $\mathrm{B}$. What is striking is this. (What I am about to say could be adapted to the view that either the gorilla or the infant has a duty to compensate.) It is not because the adult caused B harm that he has this duty; for the other agents caused B harm also. Nor is it because the adult, unlike the others, has the capacities to have duties and to compensate that he has a duty to compensate B; for any other adult in a position to compensate B would then have such a duty, and this is clearly not intended by a proponent of (1d). (This is Thomson's point in the passage quoted earlier when she says that "causality matters to us.") Thus it seems that we're being told by the proponent of (1d) that the adult has a duty to compensate B for his broken arm because he satisfies two conditions, one having to do with causation and the other having to do with the capacities to have duties and to compensate, when neither of these conditions alone would ground the duty in question. And here I would simply ask: why think that this combination of factors grounds this duty? How is it that their conjunction achieves this? I'm not alleging any inconsistency here, but merely trying to highlight the mystery that, in the absence of any argument for (1d), seems to afflict that thesis. ${ }^{21}$

It might be replied that I have neglected some further factors that may serve to distinguish the adult from the others and thus ground a duty to compensate. Perhaps the adult is at fault in his harming of B. But we must not assume this. As noted earlier, Feinberg's case is not such a case, but compensation is allegedly owed there nonetheless. So we must accept that A is not culpable for breaking B's arm and that A does not act wrongly, all things considered, in breaking B's arm. Still, we might note that the adult has the capacity to be culpable, and perhaps it is this capacity conjoined with causation (and with the capacities to have duties and to compensate) that is thought to ground a duty of compensation. But again I would simply ask: why think that this conjunction serves to ground the duty in question, when nothing short of the conjunction does?

Again, it might be retorted that I have not exhausted what distinguishes the adult, morally, from the others. Shouldn't we say that the adult deliberately, or at least wittingly, broke B's arm, whereas the other agents did not, and that this is morally significant? This isn't clear. Nothing to this effect has been presupposed so far. But it is true of Feinberg's case, and perhaps it should be presupposed. Perhaps the idea that is at issue is that A owes compensation to B when A wittingly infringes a right of B's. But if so, this is a departure from (1d), one that I shall address in Section VIII below.

In the search for something that distinguishes the adult morally from the others, some might claim (indeed, I have heard it claimed) that the adult, unlike the others, is actually responsible for harming $\mathrm{B}$, and it is this that grounds a duty to compensate $\mathrm{B}$. But we must ask what might be meant by this. Clearly more than just causal responsibility must be intended, since the other agents are no different from the adult in this regard. Presumably what is meant is that the adult is 
morally responsible for the harm (and doesn't merely have the capacity for such responsibility). But what does this amount to? I can think of three possible interpretations.

On the first interpretation, moral responsibility is understood to have three "modes" — negative, positive, and neutral — with "culpability" and "laudability" being common terms that refer to the negative and positive modes, respectively. ${ }^{22}$ Thus a person may be responsible (as the adult allegedly is), without being culpable, for some harm by being either positively or neutrally responsible for it. Let us grant that $\mathrm{A}$ is responsible, in this sense, for the harm. (I think it in fact rather odd to say that A may be laudable for the harm done to $\mathrm{B}$, but I'll let that pass.) How does this help ground a duty to compensate B? If A is not culpable for the harm, as has been assumed, but is merely neutrally or positively responsible for it, what reason can we find here for his being saddled with a duty to compensate?

On the second interpretation, moral responsibility is taken as the mark of a certain moral maturity. To be (a) responsible (person) is to be capable of making an accurate moral assessment of one's situation, of accurately determining what one's obligations are, so that one is always morally responsible, in this sense, for what one does and the consequences thereof (unless one temporarily loses the capacity in question). Let us grant that the adult is responsible in this sense, too. Again, it is hard to see how merely having this capacity, conjoined with causation (plus any of the other capacities mentioned), serves to ground a duty to compensate.

On the third interpretation, moral responsibility is taken as the mark of another sort of moral maturity. On this understanding, to be (a) responsible (person) is to be someone who takes his or her responsibilities (obligations, duties) seriously, while an irresponsible person is one who does not. ${ }^{23}$ But this won't do. Surely A may not be responsible in this way; a proponent of (1d) would want to say that even irresponsible persons have a duty to compensate their victims. Here, though, it might be claimed that A ought to be responsible, in this sense - and who would wish to disagree with this? It might further be claimed that, if A were responsible in this sense, then A would recognize his or her duty to compensate B and act on it. Isn't it irresponsible for an adult not to assume the burden of compensating those whose rights he has infringed? Isn't it the mark of full moral maturity that one takes responsibility for one's own actions, so that, even if a third party might not have an obligation, or even be at liberty, to decide upon whom the burden should finally rest when A has inculpably infringed a right of B's and thereby caused B a loss, as a mature moral agent A himself or herself should assume this burden? Isn't this, furthermore, in keeping with Bernard Williams's observations about the peculiar appropriateness of what he calls agent-regret when one has, like $\mathrm{A}$, innocently harmed someone else ${ }^{24}$ Indeed, might it not be said that one measure of the genuineness of such regret is the preparedness to compensate where and when possible? (Recall that Feinberg also mentions regret in the passage quoted at the outset.)

This seems to me to beg the very question at issue. Of course, if A has an obligation to compensate $\mathrm{B}$, then he is irresponsible if he does not compensate $\mathrm{B}$; but if he does not have this obligation, then he is not irresponsible if he does not compensate B. And it is the allegation that he does have this obligation that I am challenging. (Similarly, Williams's remarks concerning agent- regret may seem initially plausible, but I doubt their accuracy too, although I shall not venture into this territory here. $)^{25}$ 


\section{Part VII.}

In the foregoing section I have asked, "Why should this (or this, or this) be thought to ground a duty to compensate?" The force of such a question is unclear. If it is easily answered, then it clearly lacks any significant force. But I know of no easy answer in this case. If there is a "this," a ground, that has been overlooked, then again the question lacks significant force. But, again, I know of no such ground in this case. Thus I think the question, in the present context, has some force, and I hope the reader will agree. Nonetheless, it is obvious that the question lacks the force that a cogent argument against there being a duty to compensate would have.

I think that such an argument can be constructed on the basis of considerations about strict liability. For (1d) appears to sanction strict liability (in that A need not be culpable for his infringement of B's right), and yet such liability has been thought by many to be morally repugnant, involving unfairness.

The unfairness of strict liability in this context may be brought out by appealing to this principle:

(6) If $\mathrm{B}$ has suffered a loss but $\mathrm{A}$ is not culpable for this, then $\mathrm{A}$ has a (claim-)right against everyone not to be forced to compensate B for B's loss. ${ }^{26}$

This principle should not be misconstrued. It does not say that it is never possible to justify forcing an innocent person to compensate someone else for the latter's loss. What it does imply is that, if this is ever justifiable, it is so despite the former's having a right not to be so treated (unless, of course, the right has been waived). In such a case the repugnance of treating the former person in this way will have been overridden, but not eliminated.

I think that we can argue from this principle to the claim that (1d) is false. But let us first construct an argument against (lb), which is simpler to handle than (1d):

(i) (6); that is, if $\mathrm{B}$ has suffered a loss but $\mathrm{A}$ is not culpable for this, then $\mathrm{A}$ has a (claim-)right against everyone not to be forced to compensate B for B's loss.

(ii) A has inculpably infringed a right of B's and B has thereby suffered a loss.

Hence (iii) $\mathrm{A}$ has a right against everyone not to be forced to compensate $\mathrm{B}$ for $\mathrm{B}$ 's loss.

Hence (iv) A has a right against B that B not force A to compensate B for B's loss.

Hence (v) B has no (liberty-)right as regards A to force A to compensate B for B's loss.

Hence (vi) B has no (claim-)right against A that A compensate B for B's loss.

Hence (vii) A has no prima facie duty to B to compensate B for B's loss.

Hence (viii) It is not the case that, if A has infringed a right of $B$ 's, then $A$ has a prima facie duty to B to compensate B for B's loss; that is, it is not the case that (lb).

How might one try to justify the various steps of the argument? Perhaps as follows: premise (i) is assumed for the sake of argument, as is (ii); (iii) follows logically from (i) and (ii); (iv) follows logically from (iii); (v) follows from (iv) by virtue of the interrelation between claim-rights and liberty-rights; (vi) follows from (v) by virtue of the fact that a claim-right carries with it the authority (sometimes called a power-right), and thereby the liberty, to press the claim; (vii) 
follows from (vi) by virtue of the correlativity of claim-rights and duties; and (viii) follows logically from (ii) and (vii).

Still, this is problematic. First, one might of course question the first premise. I shall return to this later. A second problem concerns the move from (v) to (vi). Is it the case that a claim-right always carries with it the power, and thereby the liberty, to press the claim? In strict Hohfeldian terms, it might be argued, a claim-right does not necessarily include a power to press the claim and, even if it did, this would not necessarily imply a liberty to exercise that power. For example, concerning a case where there is a claim to the delivery of a hundred widgets, Thomson says:

If all you need to do to make me deliver the widgets is to phone and say, in your fiercest way, "DELIVER THOSE WIDGETS OR I'LL SUE!" then I am sure all is well: you really may make me deliver the widgets. But what if I am unmoved by threats to sue? What if in order to make me deliver the widgets you need to come around in person and shoot me in the foot? Presumably that will not do at all . . .27

This seems right to me. Claims are not in general such that the claim-holder is at liberty to enforce the claim. If there is a general link between claims and their enforcement, as I suspect, then it is not so straightforward; and I don't know what the link is, exactly. Still, this problem can be obviated here by the observation that there clearly are cases in which a claim-holder does have the power and, partly for this reason, is at liberty to enforce the claim (as in the case of threatening to sue) and by the stipulation that the foregoing argument is implicitly restricted to cases of this sort. For the alleged duty to compensate is supposed to apply generally, even to cases of this sort.

A third problem with the argument is this. For simplification I made use of (lb) rather than (1d). But this turns out to have been an oversimplification. For the duty to compensate that is alleged to exist is one which, it is supposed, is had simply in virtue of the original rights-infringement. Call this ground Gl. This was the reason for moving from (lb) to (1c). But presumably A's right not to be forced to compensate B that is identified in (6) is had by A simply in virtue of his being inculpable for B's loss. Call this ground G2. If we were to make explicit reference to these grounds in the argument, it would proceed as follows:

( $\left.i^{*}\right)$ If B has suffered a loss but A is not culpable for this, then A has a (claim-)right grounded in G2 against everyone not to be forced to compensate B for B's loss.

(ii) A has inculpably infringed a right of B's and B has thereby suffered a loss.

Hence (iii*) A has a right grounded in G2 against everyone not to be forced to compensate B for B's loss.

Hence (iv*) A has a right grounded in $\mathrm{G} 2$ against $\mathrm{B}$ that $\mathrm{B}$ not force $\mathrm{A}$ to compensate $\mathrm{B}$ for B's loss.

Hence $\quad\left(\mathrm{v}^{*}\right) \mathrm{B}$ has no (liberty-)right grounded in G2 as regards A to force A to compensate B for B's loss.

Hence (vi*) B has no (claim-)right grounded in G2 against A that A compensate B for B's loss. 
Hence (vii*) A has no prima facie duty grounded in G2 to B to compensate B for B's loss.

Hence (viii*) It is not the case that, if A has infringed a right of B's, then A has a prima facie duty grounded in G1 to B to compensate B for B's loss; that is, it is not the case that (lc).

It is obvious that this argument is valid only if G1 is identical with G2. But isn't it plain that these are distinct grounds?

The point being made here is simply this. Duties are owed for reasons. One can have a duty to do something for one reason and not have a duty to do that thing for some other reason. Even if the argument from step ( $\left.i^{*}\right)$ through step (vii*) is unobjectionable, what is to be concluded is that it is not the case that, if A has infringed a right of B's, then A has a prima facie duty grounded in G2 (that is, grounded in his inculpability for B's loss) to B to compensate B for B's loss. On the face of it, this is perfectly consistent with denying (viii*), that is, with asserting that it is the case that, if A has infringed a right of B's, then A has a prima facie duty grounded in G1 (that is, grounded in his having infringed a right of B's) to B to compensate B for B's loss.

But actually it is not so clear that G1 and G2 are distinct. To see why, let us distinguish between two views on moral status. On the first view, which I shall call the Simple View, whatever characteristic (or set of characteristics) it is that grounds the capacity to have duties also grounds the capacity to bear responsibility (in the sense of being laudable or culpable for one's deeds). On the second view, which I shall call the Complex View, these grounds differ. I assume that, if the Complex View is true, the grounds in question are nonetheless intimately related; in particular, whatever it is that grounds the capacity to bear responsibility includes whatever it is that grounds the capacity to have duties (so that one cannot be responsible without being able to be obligated, even if one can be obligated without being able to bear responsibility).

Now if the Simple View is true, then I think that G1 is in fact identical with G2. Remember that it is being assumed that A has inculpably infringed a right of B's, causing B a loss. What is it, then, that under the circumstances transforms A's causing B a loss into the infringing of a right of B's? Arguably, simply A's capacity to have duties. And what is it that under the circumstances transforms the causing of the loss into an inculpable causing of a loss? Arguably, simply A's capacity to bear responsibility. ${ }^{28}$ Thus, only if the Complex View is true, does it appear that we should insist that G1 and G2 are distinct.

Even if G1 and G2 are distinct, though, I think the argument can be salvaged. For then G1 would be contained in, or entailed by, G2, given that no one attains the capacity to bear responsibility without attaining the capacity to have duties. The significance of this is the following. It seems to be a general truth that where $\mathrm{C}$ is one set of characteristics and $\mathrm{D}$ is another wider set that contains $\mathrm{C}$, if one has a certain duty in virtue of $\mathrm{C}$, then if one also exemplifies $\mathrm{D}$, one has that duty in virtue of $\mathrm{D}$. If this is so, then if one has a duty to compensate in virtue of G1, one has that duty in virtue of G2; and so, if one has no such duty in virtue of G2, then one also has no such duty in virtue of $\mathrm{G} 1 .^{29}$ 
It seems to me, therefore, that the case just constructed against A's having a duty to compensate $\mathrm{B}$ rests entirely on the first premise. While it is surely a very common belief that imposition of strict liability is unfair, ${ }^{30}$ still this premise might be questioned. It might be claimed, for example, that it is strict liability to punishment in particular, rather than to penalty in general, that is unfair. But why think so? What makes strict liability repugnant is the suffering that is imposed, and penalties (such as enforced compensation) generally involve suffering, whether or not they are tantamount to punishment. ${ }^{31}$

Still, some have argued that the repugnance of strict liability can be (not just overridden but) eliminated in certain contexts, the present context of compensation for rights-infringements included. Honore is among them. He says:

Our actions impinge on others, who resent it if the effects on them are harmful. So we are, unless indifferent to the reaction of others, forced to gamble in order to acquire credit and esteem and avoid exposure to discredit and resentment ... [A]s members of a community, we know that we will be held responsible for whatever good or ill we cause ...

[W]e live under a system by which a community allocates responsibility according to outcomes, and we are consequently forced to make bets on those outcomes ... Not only are actions and outcomes conventionally allocated to people but we and others are entitled to insist that they should be so allocated...

Given certain conditions outcome-allocation can be defended as fair. The necessary conditions are that the system must in its operation be impartial, reciprocal and over a period beneficial ... This makes it unfair to apply the system to the incapable, for whom there is no likely surplus of benefit over detriment. But for the capable the three conditions are normally satisfied. All those who possess a minimum capacity stand to profit from the system of outcome-allocation most of the time... ${ }^{32}$

These remarks are complex. At bottom, though, Honore's contention seems to be that, if A has inculpably infringed a right of B's, then it is fair (not unfair) to force A to compensate B for B's loss if A is "capable" (and if the system is impartial, reciprocal, and generally beneficial). But why should this be accepted? Here Honore says the following:

Presumably a person should not be strictly liable if he did not understand the system by which in a society ... people are held accountable for the good or bad outcomes ... Strict liability, like fault liability, should require the appropriate capacity. But there is a distinction between not understanding the system and not appreciating the risk involved in a particular choice, e.g. to ... store explosives. ${ }^{33}$

The suggestion seems to be that, when one is in general aware that a system of strict liability will be enforced (even if one neglects this on occasion) and one acts anyway, then being held strictly liable for one's action is not unfair. Now, I think that this is quite correct, in certain cases. For in certain cases acting anyway would appear to constitute a waiving of the right not to be forced to compensate for a loss that one has inculpably caused. ${ }^{34}$ If this is so, then there is no unfairness after all in holding the agent liable. But surely this is not so in all cases, for the agent may not 
consent to the system that is imposed by others. ${ }^{35}$ Suppose that a man, who is unfairly held prisoner, is told that, if he attempts to escape, he will be hanged. We cannot construe an attempt to escape on his part as a waiving of his right not to be so mistreated.

Honore has an answer to this. He says:

A further point which bears on the fairness of outcome-allocation and so of strict liability is that neither is something which the person subject to them has chosen. Does that make these institutions morally dubious? We have never made a social contract providing for outcomeallocation, still less for strict liability. They bind us willy-nilly.

It is true that we have no choice in the matter. But outcome-allocation can [nonetheless] be defended . . . For outcome-allocation is crucial to our identity as persons; and, unless we were persons who possessed an identity, the question of whether it was fair to subject us to responsibility could not arise. If actions and outcomes were not ascribed to us on the basis of our bodily movements and their mental accompaniments, we could have no continuing history of character...

In the real world, fortunately, human bodily movements and their mental accompaniments are with some exceptions interpreted as actions and decisions. They are ascribed to authors, who accordingly count as persons; and it is by virtue of these ascriptions that each of us has a history, an identity and a character. But there is a price to be paid for being a person. As the counterpart of this status we are responsible for our actions and their consequences, and sometimes this responsibility exposes us to legal sanctions. ${ }^{36}$

Again, these remarks are complex. But their gist seems to be this. People have no choice but to be held accountable for the outcomes of their decisions and actions, since this is essential to their being recognized and treated as persons, something which cannot be unjust. I'm not sure what this means. By "have no choice" Honore might mean that this is something to which people cannot help but consent; or he might mean that this is something to which people cannot give consent and from which they cannot withhold consent. On the first reading, he seems to be saying that people cannot help but waive their right not to be held strictly liable for the outcomes of their rights-infringements, since this is essential to their being recognized and treated as persons (and, presumably, people cannot help but wish to be so recognized and treated, and they cannot help but see that being held strictly liable for their actions is essential to this). On the second reading he seems to be saying that the injustice of strict liability is somehow eliminated in this context simply because recognizing and treating people as persons — as the authors of their decisions and actions - in fact requires that they be held strictly liable for the outcomes of their rights- infringements. On either reading he seems to me utterly mistaken, and that is because it simply is not true that recognizing and treating people as the authors of their decisions and actions requires that they be held strictly liable for the outcomes of these decisions and actions. For otherwise excuses would be a conceptual impossibility, which they manifestly are not.

Some may object, finally, that throughout all of this I have lost sight of the simple fact that, in cases of the sort under discussion, some innocent person has to suffer. Either B suffers (from the 
loss inflicted by A) or else A does (through being forced to compensate B, so that B's suffering is in a sense annulled). Strict liability of some sort is thus inevitable. Why victimize B rather than A, which is what a rejection of (1d), conjoined with an acceptance of (6), would require? ${ }^{37}$ In fact, there is surely good reason why A rather than B should bear the cost. Consider a case where compensation is owed but where this is not due to the infringement of a right. Suppose that A needs some medicine at noon and (justifiably) goes to B's store to purchase it. B gives A the medicine, and A owes B compensation for this. Now compare this with a Feinberg-like case where A needs the medicine at midnight and (justifiably) breaks into B's store to get it. If A owes B compensation in the first case, why not in the second case also? And if he does owe it in the second case, doesn't this show that Feinberg is right after all?

No, it doesn't. Let us agree that A owes B compensation for the medicine in the first case. Why is this? Clearly it is not due to any rights-infringement; it seems, rather, to be due to the fact that there is some antecedent, perhaps implicit agreement between A and B that, if B gives A the medicine, then A will pay B for it. Perhaps something similar can be said in favor of the claim that A owes B compensation in the second case, also. I am somewhat dubious about this, ${ }^{38}$ but that is beside the point. The point is simply this, and it is twofold. First, the cases just given provide no reason to doubt that (6) - the key premise in the argument against (1d) — is true; for, I believe, if an innocent person, A, willingly enters into the sort of agreement that is at issue in the first case and perhaps in the second, then he thereby waives his right not to be forced to compensate B for B's loss. Second, if the principle concerning agreement (whatever it is, exactly) that explains a duty to compensate in the first case applies also to the second case and thus explains a duty to compensate in that case too, it is not a principle that makes any reference to the infringement of a right. Hence it provides no support for (1d).

But even if this is right, still it might seem that, if strict liability is inevitable, there is at least as good a reason to have A bear the cost of B's loss as to have B bear it. But I deny this. I deny that strict liability is inevitable. Of course, I accept that, in cases of the sort under discussion, the suffering of some innocent is unavoidable. In that sense, life is just unfair. We can surely agree that B does not deserve to suffer at A's hands; we might even say that B deserves not to suffer at A's hands; and we can say, at least in the case of the adult, that $\mathrm{B}$ has a right not to be made to suffer by A. All of this indicates, I believe, that it would be morally desirable if B could somehow be compensated for his loss. What I don't see is how any of this indicates that A is obligated to B to compensate B for his loss. The chips have fallen - and, remember, A is not to be blamed for their having fallen as they have. Why believe that $\mathrm{A}$ is obligated to assume the burden? Moreover, if it is B who must live with this burden in the cases of the hurricane, gorilla, and infant (as, I take it, even the proponents of (1d) will agree), then, again, why not in the case of the adult also? If $\mathrm{A}$ is made to compensate $\mathrm{B}$, he is being held strictly liable for B's loss, and a right of his is thereby infringed; if B is left to shoulder the burden on his own, he is not being held strictly liable, and so no similar right of his is thereby infringed.

\section{Part VIII.}

I hope I have succeeded in casting serious doubt on (1d). Some may disagree, saying: "There is a strong intuition that strict liability is morally repugnant; there is a strong intuition that compensation is owed in cases of rights-infringement. You have shown that these intuitions conflict. But you haven't shown why we should favor the former over the latter." I grant that I 
have not argued in favor of (6). Even so, given (6)'s strong intuitive plausibility, the argument surely casts doubt on (1d). Perhaps (1d) also casts doubt on (6), but that is a separate matter. Furthermore, I have not relied solely on (6) in my attack on (1d). Sections (V) and (VI) have adduced independent considerations against (1d).

Others may be somewhat more charitable, and agree that I have cast doubt on (1d), but still say, "So what? It's not (1d) but some other, more restrictive principle linking rights-infringement with compensation that should be the focus of discussion." There is evidence that Thomson herself would say just this. At one point she contrasts A's causing B a loss "by some freak accident" with A's causing B a loss "freely and wittingly" (as in Feinberg's case), and she says that in the second case, but not the first, A is liable for B's costs. ${ }^{39}$ At another point she says that in certain cases my justifiably infringing a relatively unimportant property right of yours in order to save someone's life requires not that I alone bear the burden of your loss (by way of compensating you) but that we together share this burden. ${ }^{40}$ And we might add: what about the case where it is your life that I save? Does anyone really want to say that I still owe you compensation for the damage done to your property? These and other such considerations suggest that (1d) requires emendation by tacking on some further conditions, such as any or all of the following:

if A's infringement of B's right was witting;

if B doesn't benefit from the infringement;

if A benefits from the infringement.

But while I welcome such further restrictions to the thesis that there is a duty to compensate for rights-infringements, none of them is adequate, I think, as long as the condition that $\mathrm{A}$ is culpable is not included. Let us briefly examine a series of three cases where A's infringement of B's right is witting but where just who benefits from the infringement varies. ${ }^{41}$

Suppose first of all that A wittingly breaks B's arm in the course of saving B from being run over by a truck. B benefits thereby, but A doesn't. I am of course quite willing to grant that A does not owe B compensation in this case. But obviously this doesn't imply that A does owe B compensation in similar cases where B doesn't benefit or where A does. Perhaps a proponent of (1d) would say that this case does not undermine his thesis, claiming that the thesis concerns only net losses on B's part. I suspect, though, that this would be a misrepresentation of what at least some people would want to say. Consider a variation on the case where A breaks B's arm, thereby saving B's life, but where A could have saved B's life without inflicting such serious damage. Once again, there is no net loss, but I suspect that some would say that compensation is called for. If they would, I would, in response, simply appeal to the argument from the repugnance of strict liability, as before.

What if A pushes B to save C's life? Here C benefits, but neither A nor B does. The argument from the repugnance of strict liability still seems to me to apply in this case. Neither A nor C owes B compensation.

What, finally, if A himself benefits? Suppose that he justifiably pushes B, breaking his arm, in order to save his, A's, life. This most closely resembles Feinberg's case: when you break into the cabin, it is to your benefit to do so (or, at least, you prevent harm from coming to you by doing 
so). Even here I would simply invoke the argument from the repugnance of strict liability. The fact that the rights-infringer benefits from the infringement seems to me wholly irrelevant. Let me quote from an unlikely ally here. Kagan says:

If I destroy some of your property in the course of saving my life, I may be faultless — but I have an obligation to compensate you later nonetheless. And the seemingly obvious explanation of this has to do with your having a property right over the object in question. Given that I was morally justified in destroying your property it may be inappropriate to say that your rights were "violated"; but it still seems that your rights were "infringed," and it is this very fact that explains why I owe you compensation for the damages. What's more, it is - after all - only fair compensation that I owe you: I need to compensate you for the harm I have done you. I do not need to give up something equivalent to the gain I have made; in particular, I do not need to give up something equal in value to my life! In short, the focus of concern is upon the victim's right; not upon the fault or gain of the agent. ${ }^{42}$

Of course, I reject the claim that there is a duty to compensate in this case, but what is useful here (for my purposes) is Kagan's insistence that, even from the point of view of those who accept this claim, the fact that the agent benefits or gains from the infringement is irrelevant to the question of whether or not there is a duty of compensation.

It might be objected that simply appealing to the argument from the repugnance of strict liability in these three cases won't do. For, it might be said, we shouldn't accept (6) as it stands. Rather, what we should accept is the claim that, if B has suffered a loss and A is not culpable for this and A did not wittingly cause it, then A does have a right not to be forced to compensate B for B's loss; but if A did wittingly cause it, then A doesn't have this right. But while I concede, once again, that I have not argued in favor of (6), let alone in favor of it over this more restrictive alternative, I think it must be granted that this alternative is problematic. In each of the three cases just cited it would of course imply, as intended, that A owes B compensation, but note that it would imply this even if A acted laudably and/or was obligated to act as he did. That A should be burdened with compensating B in such circumstances seems especially ironic, since he could have avoided this burden simply by acting in a morally inferior way. Of course, the objector might respond by saying that (6) should be qualified even further in order to take this possibility into account, but here I decline to follow him. For the basic intuition underlying (6) is, I think, not so complicated. It is simply that innocence warrants protection.

\section{Part IX.}

What, finally, if $\mathrm{A}$ is at fault in his infringement of B's right?

I have acknowledged two readings of "at fault" in this context: A's infringement was wrong or unjustifiable, all things considered; and A was culpable for the infringement. With respect to the first: if the infringement was wrong but A was inculpable, the consideration about strict liability still pertains. With respect to the second: here of course this consideration does not pertain. Might we then say this?

(1e) If A has culpably infringed a right of B's, then A has a prima facie duty to B, in virtue of this fact alone, so to act that B is compensated for his loss (etc., as in (1d)). 
Even this is to be doubted.

I think that it may be true that someone, A, who is culpable for some action deserves to be forced to suffer in some way. ${ }^{43}$ And I have already said that I think it plausible that a right-holder, B, who has suffered a loss deserves to be compensated for this loss. Now, it could on occasion be that the best way to meet both desert-based demands is to force A to compensate B, but I see no necessity that this be so, especially when it is recognized that there can often be culpable behavior that infringes no one's rights and that there can often be rights-infringements brought about by inculpable behavior. A better system (one that better meets the demands of justice) might be to have separate "pools," one to which culpable persons must contribute and another from which victims of rights-infringement may draw, without trying to match up A's contribution with B's withdrawal, even in cases where A is culpable for his or her infringement of B's right. ${ }^{44}$ Is there any "moral loss" associated with such an arrangement? That is, is there any demand of justice that such an arrangement fails to satisfy? I cannot see that there is. And if there isn't, then (le), too, is false. A doesn't owe compensation to B. ${ }^{45}$

\section{Footnotes}

1. Joel Feinberg, Rights, Justice, and the Bounds of Liberty (Princeton: Princeton University Press, 1980), p. 230.

2. Judith Jarvis Thomson, Rights, Restitution, and Risk (Cambridge: Harvard University Press, 1986), p. 71. Henceforth I shall refer to this book as "Thomson 1."

3. Others, too, might think it false, but I shall try to advance fresh reasons in this paper. I have in mind Jules Coleman in particular, who in a series of papers (some of which are gathered in his Markets, Morals and the Law (Cambridge: Cambridge University Press, 1988)) has argued that in such cases the victim has a right to compensation, due to considerations of what Coleman calls corrective justice, but that the victimizer need not be obligated to provide compensation. Coleman thus seeks to separate the issue of recovery from that of liability. I find this strange, in that, in standard cases at least, it is hard to see against whom it might be that the victim has a right to compensation if not against the victimizer himself. At any rate, in this paper I shall be suggesting that the victim need have no right to compensation at all.

4. These two aspects of the duty must be kept distinct. In other cases A may owe it to B to compensate not B but $\mathrm{C}$.

5. See Michael J. Zimmerman, An Essay on Moral Responsibility (Totowa: Rowman and Littlefield, 1988), pp. 41-43.

6. Feinberg, op. cit., p. 230; Thomson 1, p. 71.

7. Other reasons to accept this possibility include whatever reasons there are to think that rights constitute prima facie (and sometimes merely prima facie) moral considerations. If one holds rights to be correlative with duties, and duties to be prima facie; if one is impressed by the problem of specifying the content of rights, when rights are not treated as prima facie moral considerations; if one accepts the possibility of conflicts of rights but rejects the possibility of irresolvable moral dilemmas - if any of these apply to one, as they do to me, then one will have reason to accept that (3) falls short of (4).

8. Shelly Kagan, "Causation and Responsibility" (American Philosophical Quarterly 25 (1988): 293-302), p. 299. 
9. Ibid.

10. Ibid.

11. Ibid.

12. Thomson 1, pp. 201-2. "A" and "B" have been intersubstituted to conform with earlier formulae.

13. Of course, for this claim to be plausible, it would have to be qualified. One can owe compensation in the absence of infringing a right — when a bill becomes due, for instance. Thomson is quite aware of this (Thomson 1, p. 77).

14. Judith Jarvis Thomson, The Realm of Rights (Cambridge: Harvard University Press, 1990), pp. 273-74. Henceforth I shall refer to this book as "Thomson 2."

15. Thomson 2, p. 262.

16. Thomson 2, p. 250.

17. What appeal does the Limits Thesis have? What, at any rate, are Thomson's reasons for endorsing it? She confesses herself unable to prove it true (Thomson 2, p. 280) but embraces it after having conducted a survey of the relevant normative terrain. In particular, she rules out as genuine claims various candidates that others have proposed (such as a claim not to be coerced or a claim against eavesdropping). I find her discussion persuasive, but this is not the occasion to attempt to evaluate it.

18. Thomson 2, p. 215.

19. Utilitarianism, unadorned, would appear to have this implication.

20. See Zimmerman, op. cit., pp. 40-47.

21. Contrast the case of being a male sibling. Being a male is (necessary but) not sufficient for being a brother, and being a sibling is likewise (necessary but) not sufficient for being a brother, but being a male sibling is (both necessary and) sufficient for being a brother. Here, though, there seems to be no mystery; it is plain to see that nothing more is required for being a brother than the conjunction of these two conditions. But the case at hand is not like this. Plainly, having the capacities to have duties and to compensate is (necessary but) not sufficient for having a duty to compensate; in addition, having caused harm is not sufficient (nor is it necessary) for having this duty. But, in addition, it seems that it is not plain to see that nothing more is required for having this duty than the conjunction of these two conditions.

22. I know of no common term for the neutral mode. In Zimmerman, op. cit., pp. 61-62, it is referred to as "indifference-worthiness."

23. See Graham Haydon, "On Being Responsible" (Philosophical Quarterly 28 (1978): 4657), for further discussion of this.

24. Williams, Moral Luck (Cambridge: Cambridge University Press, 1981), pp. 27-30.

25. The matter is complicated by the fact that there are a number of relevant emotions to be taken into account, in particular those of remorse and shame as well as regret. See Irving Thalberg, "Remorse" (Mind 72 (1963): 545-55); Leonard Boonin, "Guilt, Shame and Morality" (Journal of Value Inquiry 17 (1983): 295-304); Gabrielle Taylor, Pride, Shame, and Guilt (Oxford: Clarendon Press, 1985); and Zimmerman, op. cit., pp. 134-35.

26. Here "not culpable" is to be understood to be tantamount to "inculpable." See note 28 below.

27. Thomson 2, p. 108.

28. Unless one can bear responsibility, one is merely not culpable rather than inculpable. People are innocent; chairs are not. 
29. It may seem that the following is a counterexample to the general principle invoked here. Suppose that $\mathrm{C}$ is the property of being a faculty member and $\mathrm{D}$ is the property of being a department chairman. It may be that regular faculty members must teach three courses but department chairmen only one, and yet all department chairmen are faculty members. The proper response to this is that the duty to teach three courses isn't grounded in C alone; it is grounded in C-minus-D, that is, in the property of being a "regular" faculty member, as opposed to a faculty member who is also a department chairman. At best, then, this gives support to the view that a duty to compensate is grounded in G1-minusG2; but those who advocate (1d) don't restrict its application to those few people (if any) who can have duties but not bear responsibility.

30. For a classic discussion, see H. L. A. Hart, Punishment and Responsibility (Oxford: Clarendon Press, 1968), especially chapters 6 and 7.

31. Punishment may involve an especially vile form of suffering, and so strict liability to punishment in particular may be especially repugnant, but that does not alter the present point. As Honore (someone who defends (1d)) says: "[W]e do not think that in criminal law the innocent who lack mens rea should be fined rather than imprisoned. We think they should be acquitted." See Tony Honoré, "Responsibility and Luck" (Law Quarterly Review 104 (1988): 530-53), at 534.

32. Honoré, op. cit., pp. 540-41.

33. Honoré, op. cit., p. 542.

34. See Zimmerman, op. cit., p. 178.

35. The force of this observation extends beyond the rejection of (1d). Some may seek to ground A's duty to compensate B not, as (1d) does, in A's having infringed a right of B's in causing B a loss, but in A's having caused B a loss in some other way. For example, it might be claimed that property rights are best understood not in terms of one's having a right that others not make unauthorized use of one's property, but rather in terms of one's having a right that others not make such use of one's property unless such use is a matter of "necessity," in which case one has a right to compensation for the use. If so, then, contrary to what Feinberg and Thomson say, no infringement of a right occurs in the cabin-case; still, compensation is called for. There may be something to this view, but it cannot be accepted without qualification. For the protection that innocence warrants when A inculpably causes B a loss is warranted whether or not A thereby infringes a right of B's. Hence, if the foregoing argument against (1d) is sound, it can be similarly argued that A must waive his right not to be forced to compensate $\mathrm{B}$ if he is to have a duty to $\mathrm{B}$ to do so, whether or not his causing B a loss constitutes an infringement of a right of B's.

36. Honore, op. cit., p. 543.

37. Cf. Coleman, op. cit., pp. 174-82.

38. Just how "implicit" can an agreement be and still ground a duty to abide by it?

39. Thomson 1, pp. 202-3. It is not clear to me that what Thomson says here accords with what most people would say. If your guest breaks your wine glass quite by accident and without negligence — everyone is saying "Cheers!" and clinking glasses; he clinks his glass no harder than the others, but only the glass that he holds breaks - would you not expect him to offer to replace it (even if you would, graciously, decline the offer)? And what if the object were much more valuable? Would you be content to say, wittily, "Those are the breaks!" and leave it at that? Perhaps, though, these don't count as "freak" accidents. 
40. Thomson 1, pp. 64-65.

41. In certain of her writings, Thomson appears to suggest that a rights- infringement cannot be unwitting (see her "Causality and Rights: Some Preliminaries" (Chicago-Kent Law Review 63 (1987): 471-96)), but at other times she clearly allows for this possibility (see Thomson 2, p. 229). I think that we should accept the possibility; at least, we should accept that it is possible that someone should unwittingly fail to fulfill his duty to accord someone else that to which the latter has a right (whether or not we call this a matter of "infringement").

42. Kagan, op. cit., pp. 298-99.

43. Zimmerman, op. cit., pp. 164-79.

44. See Coleman, op. cit., p. 185; see also his "On the Moral Argument for the Fault System" (Journal of Philosophy 71 (1974): 473-90), esp. 484 and 490.

45. Versions of this paper were presented to audiences in Chapel Hill and Davidson. I am grateful to all those who made comments on those occasions, and in particular to Angela Curran, Irwin Goldstein, Roderick Long, Gerry Postema, Andy Reath, Geoff SayreMcCord, and David Schmidtz. I am grateful also to Doug Husak and, especially, Terry McConnell for comments made on other occasions. Finally, I am grateful to an anonymous referee for some penetrating and helpful comments. 